\title{
A PROPÓSITO DO TÍTULO A HERMENÊUTICA DO SUJEITO ${ }^{1}$
}

\section{About the title The hermeneutics of subject}

\author{
Salma Tannus Muchail \\ Professora titular do Departamento de Filosofia, Professora emérita da PUC-SP, São Paulo, SP \\ - Brasil, e-mail: salma@pucsp.br
}

\begin{abstract}
Resumo
Introduzindo a observação sobre a coerência entre forma e conteúdo do Curso de 1982, é preciso perguntar pela coerência entre o Curso e seu título, já que nem forma nem conteúdo parecem corresponder exatamente ao que seria uma hermenêutica do sujeito. Por um lado, o título não é compatível com o Curso na medida em que este não se ocupa preferencialmente com o sujeito enquanto "conhecimento de si” mas enquanto "cuidado de si” o qual não é, de fato, assunto da hermenêutica. Por outro lado, o título tem duplo sentido: do ponto de vista histórico, o Curso ocupa-se com as condições que tornam possível o que viria a ser uma hermenêutica do sujeito, enquanto que do ponto de vista genealógico ele trata das possibilidades de superação do que veio a ser
\end{abstract}

Este texto foi apresentado no Colóquio Internacional Foucault: nouveaux déploiements, Paris, 2004. A versão francesa foi publicada com “À propos du titre L' Herméneutique du sujet”, Cahiers Parisiens, Paris, v. 1, n. 1, p. 349-356, 2005. 
uma hermenêutica do sujeito. Portanto, a coerência da relação entre o título e o que ele designa reside nesta ambiguidade.

Palavras-chave: Hermenêutica. Sujeito. Verdade. Conhecimento de si. Cuidado de si. Genealogia.

\begin{abstract}
Beginning from the observation that there is coherence between the form and the contents of this 1982 course, one must question the coherence of the course's title, since neither form nor contents seem to correspond exactly to what a hermeneutics of the subject would be. On the one hand, the title is not compatible with the course, since the latter does not deal with the subject constituted by "knowledge of the self", but rather with the subject constituted by "care of the self", whose truth is not produced by a hermeneutics. On the other hand, the title has a double meaning: from a historical point of view, the course deals with the conditions that make what would become a hermeneutics of the subject possible, while from a genealogical point of view, it takes up the possibilities of going beyond a hermeneutics of the subject. Therefore, the coherence of the relationship between the title and that which it designates resides in this ambiguity.
\end{abstract}

Keywords: Hermeneutics. Subject. Truth. Knowledge of the Self. Care of the Self. Genealogy.

O Curso que Foucault proferiu em 1982, A Hermenêutica do sujeito - palavra pronunciada - desenvolve-se na forma de retomadas sucessivas, recolocações de temas e autores, detalhamentos graduais, apresentando aos seus ouvintes não tanto as conclusões mas o movimento ou o exercício da própria investigação: uma composição "empírica”, um procedimento "passo a passo", “um laboratório vivo”, "um novo estilo de ensino”, escreve F. Gros. ${ }^{2}$

2 Estas são algumas expressões usadas por GROS, F. no texto que acompanha a edição do livro, para caracterizar "a singularidade do curso de 1982". "Situação do curso". FOUCAULT, 2001, p. 499-503. 
De igual maneira, o livro - palavra escrita - adquirindo forma na atividade da reelaboração do curso, apresenta-se aos leitores menos como "realização de um programa teórico" que como "lugar de uma experiência, de um ensaio" (GROS, 2001, p. 490).

Ora, podemos dizer que uma semelhança também existe entre o estilo do dito e do escrito e o conteúdo investigado. Com efeito, tendo o sujeito como seu eixo central, o sujeito de que se ocupa não é aquele cuja natureza ou identidade já está constituída, mas aquele que se autoconstitui em práticas de si.

Entretanto, é justamente esta espécie de coerência entre forma e conteúdo que parece abalada quando se atenta para o título do curso e do livro. É a suspeita que espreita o tradutor quando, ao cabo do laborioso ofício de traduzir, surpreende-se a levantar uma estranha hipótese: a de que, afinal, nem forma nem conteúdo parecem corresponder exatamente ao que seria uma hermenêutica do sujeito. É sobre esta hipótese que sugerimos algumas reflexões. Propomos desdobrá-la em duas questões: primeiro, o título é incompatível com o que ele designa? Segundo, o título faz sentido?

\section{A incompatibilidade do título}

O Curso de 1982 tem seu ponto de partida na distinção (ou oposição) entre cuidado de si e conhecimento de si. Esta oposição fundamenta outras que, por assim dizer, lhe são correlatas. Assim, esquematicamente, pode-se falar em modos distintos de reflexividade ou de linhagens de pensamento filosófico, relativas a duas vias de acesso à verdade, em épocas históricas distintas e, principalmente, a duas noções opostas de sujeito. Ao cuidado de si corresponde a linhagem espiritual do pensamento segundo a qual o acesso à verdade é alcançado por atos ou práticas envolvendo e transformando todo o ser do sujeito. Ao conhecimento de si corresponde o pensamento de tipo representativo segundo o qual o acesso à verdade é privilégio do sujeito em razão de sua própria e inalterável estrutura, precisamente, a de ser sujeito cognoscente. No primeiro caso, trata-se da tradição que caracteriza o sujeito antigo, sujeito que se constitui em técnicas ou exercícios de conversão a si, nos quais sua verdade pode ser lida ou descrita. No segundo caso, trata-se da tradição que caracteriza o sujeito moderno, sujeito que tem uma identidade já dada, na qual se aloja sua própria verdade, verdade do ou no sujeito, a ser descoberta ou decifrada. O primeiro polo destas oposições encontra seu marco filosófico principal no pensamento helenístico e romano, com realce para o estoicismo, enquanto o segundo polo se 
consolida no cartesianismo. A origem filosófica de ambos, porém, se situa nos paradoxos do platonismo que, abrindo a dupla via do cuidado de si e do conhecimento de si deu lugar tanto à linhagem da espiritualidade quanto à do saber representativo. Uma descrição sucinta desta espécie de bifurcação originária pode ser lida em um trecho de Francesco Paolo Adorno sobre "os dois caminhos" seguidos pela filosofia desde Platão: "o de uma estilização da existência e o do exame do sujeito de conhecimento, correspondendo, entre outros, a duas maneiras de definir o eu"3 (ADORNO, 1996. p. 121).

Este esquema de oposições, suporte das ideias então desenvolvidas por Foucault, é reconhecido em vários estudos sobre o curso 1982 ou sobre o livro que o transcreve. ${ }^{4}$ Eis, por exemplo, algumas distinções que F. Gros, na "Introdução" do volume Foucault et la philosophie antique, estabelece: de um lado, "o sujeito do conhecimento de si”, que tem uma "identidade”, uma "constituição profunda”, uma "verdade íntima”, uma "natureza secreta” e que responde a uma questão que é principalmente "cristã", a questão - "quem somos?”; de outro, o "sujeito do cuidado de si”, que se constitui como "sujeito de ação", sujeito ético e político, sujeito que se reinventa, e que corresponde à questão, grega de origem - "que devemos fazer de nós mesmos?” (GROS, 2003, p. 10-13).

Também no texto "Situação do curso", F. Gros explicita estas oposições. Numa frase, sintetiza: "a oposição entre a Antiguidade e a idade moderna é então cunhada de modo diferente, mediante duas alternativas

3 Uma análise deste tema é encontrada no estudo de Anissa Castel-Bouchouchi, "Foucault et le paradoxe du platonisme”, incluído no volume Foucault et la philosophie antique (sous la direction de GROS; LÉVY, 2003, p. 175-193).

4 O texto de F. P. Adorno, por exemplo, que acabamos de mencionar, reconstitui estas oposições, muito particularmente em dois momentos de seu último capítulo, sob os títulos "Spiritualité et philosophie" e "Entre souci de soi et connaissance de soi” (ADORNO, 1996, p. 119130). No volume Foucault et la philosophie antique, resultado de um colóquio que se seguiu à publicação do livro, diferentes autores fazem referência a estas oposições. Leia-se, por exemplo, a retomada da denominação "saber espiritual" e "saber de conhecimento" no ensaio de Thomas Bénatouïl, "Deux usages du stoïcisme: Deleuze, Foucault” (p. 41). Ou ainda, a passagem onde Laurent Jaffro, no ensaio "Foucault et le stoïcisme - sur l'historiogrphie de l'herméneutique du sujet“, sistematiza em cinco pontos "o conjunto de oposições estruturam o Curso” (p. 69-70). Eis a lista, resumidamente: 1. Oposição entre a concepção estoica de exercício e a concepção cartesiana de método; 2. Oposição entre "saber de espiritualidade" e "saber de conhecimento"; 3. Oposição entre exercício no sentido estoico e exercício no ascetismo cristão; 4. Oposição entre o exercício estoico do dizerverdadeiro e o exercício cristão da confissão; 5. Oposição entre exercício e sujeição à lei. 
conceituais, entre filosofia e espiritualidade, entre cuidado de si e conhecimento de si”. Distingue o sujeito moderno, "a priori capaz de verdade” e o sujeito antigo, "sujeito ético de ações retas” (GROS, 2001, p. 503-504). De um lado, a "descrição" da verdade, que pode ser "lida” nas práticas e posturas; de outro, a "decifração" da verdade na intimidade das almas ou "no segredo das consciências” (GROS, 2001, p. 503-504).

Estas oposições orientam, por assim dizer, a descrição histórica que Foucault realiza e as escolhas que faz para realizá-la. Na primeira hora da primeira aula (de 06 de janeiro de 1982), ao introduzir o tema do cuidado de si como um fenômeno cultural decisivo na história do pensamento, afirma:

Temos pois, com o tema do cuidado de si, uma formulação filosófica precoce, por assim dizer, que aparece claramente desde o século $\mathrm{V}$ a. C. e que até os séculos IV-V d. C. percorre toda a filosofia grega, helenística e romana, assim como a espiritualidade cristã (FOUCAULT, 2001, p. 13).

Deixa claro, particularmente na segunda hora desta primeira aula, que a organização de um estudo sobre a história do cuidado de si comportaria, esquematicamente, três momentos: o momento socrático-platônico, do seu nascimento filosófico; o momento da "idade de ouro" de seu desenvolvimento na "cultura de si" helenística e romana dos séculos I e II d.C.; e o momento da passagem para o ascetismo cristão, nos séculos IV e V (FOUCAULT, 2001, p. 32). Estas duas horas da primeira aula também situam a importância do "momento cartesiano" na desqualificação do cuidado de si e na requalificação do conhecimento de si. Contudo, como se sabe, o Curso de 1982 não percorrerá todos estes momentos ou não os abordará na mesma proporção. A análise do momento socrático-platônico ocupa somente as duas primeiras aulas (de 06 e 13 de janeiro), embora existam remissões a seu respeito ao longo de todo o Curso. As referências ao cristianismo são breves e Foucault efetivamente não as desenvolve. Também não desenvolve o mencionado "momento cartesiano". Assim, a aproximação histórica do Curso, em magnitude e em detalhes, é de fato consagrada ao estoicismo e ao epicurismo, mais ao primeiro que ao segundo.

Mas estas escolhas confirmam que não se trata apenas de uma descrição cujo interesse é estritamente histórico. Trata-se de uma genealogia:

Parece-me - afirma Foucault, no início do Curso - que a aposta, o desafio que toda história do pensamento deve suscitar, está precisamente em apreender o momento em que um fenômeno cultural, de dimensão determinada, pode efetivamente constituir, na história do pensamento, 
um momento decisivo no qual se acha comprometido até mesmo nosso modo de ser de sujeito moderno” (FOUCAULT, 2001, p. 11).

Como convém a uma tarefa genealógica, a partir da recuperação histórica do cuidado de si e de seus termos correlatos - a verdade praticada, o sujeito das ações - realiza-se uma estratégica reflexão voltada para a atualidade, sugerindo novos modelos e práticas, possibilidades e alternativas. ${ }^{5}$

Frédéric Gros, em sua "Situação do Curso", mostra que Foucault faz aparecer "uma outra figura do sujeito”; “um novo pensamento” ou "uma ideia nova” sobre a verdade e sobre o sujeito; "novas formas de subjetividade” (GROS, 2001, p. 494, 506, 508, 524).

E na "Introdução" a Foucault et la philosophie antique escreve ele: "É para isto que Foucault se põe a lidar com a filosofia grega, para encontrar com o que superar os procedimentos de conhecimento de si na direção de outras práticas subjetivas.” (GROS, 2003, p. 11).

Estas observações mostram bem que o Curso de 1982, quer do ponto de vista estritamente histórico, quer do ponto de vista genealógico, debruçase precisamente sobre um dos pólos daquele esquema de oposições que lhe serve de suporte. Segue-se, portanto, que o sujeito com o qual se ocupa é $o$ sujeito do cuidado de si. Em contrapartida, uma hermenêutica do sujeito ao menos no seu sentido mais geral, e Foucault não fornece nenhum outro mais específico - remete precisamente ao outro pólo, aquele onde se situa uma verdade do sujeito passível de descoberta ou de decifração.

Assim, retomando uma expressão de F. Gros acerca da questão “quem somos?" parece que a hermenêutica do sujeito "é sobretudo uma questão estranha para Foucault” (GROS, 2003, p. 10). E não nos surpreende encontrar, em seu Resumo do Curso, esta passagem explícita:

\footnotetext{
5 A este respeito, convoquemos, mais uma vez, alguns autores já citados. Francesco Paolo Adorno, por exemplo, faz ver aí a proposta de "uma forma de subjetivação como alternativa àquela que é proposta pelo poder, uma subjetividade 'outra'”; remete “às modalidades pelas quais a filosofia constituiu-se como uma estilo de vida alternativo àquele considerado 'normal'”; refere-se à "invenção" da subjetividade como possibilidade de alternativa (FOUCAULT, 2001, p. 102-103, 123). Thomas Bénatouïl escreve que "Foucault pôde encontrar - e se ele não o fez, nós o podemos fazer - no ‘modelo helenístico', um modelo para conceber a filosofia tal como pretendia praticá-la”; que "o cuidado de si helenístico e romano constitui uma verdadeira alternativa ao modelo platônico e ao modelo cristão"; que este modelo "fornece assim um quadro para reinventar os papéis que o saber pode desempenhar na resistência ao poder, através da dimensão da subjetivação” (FOUCAULT, 2001, p. 38-42).
} 
Temos, portanto, todo um conjunto de técnicas cuja finalidade é vincular a verdade e o sujeito. Mas é preciso bem compreender: não se trata de descobrir uma verdade no sujeito nem de fazer da alma o lugar em que, por um parentesco de essência ou por um direito de origem, reside a verdade; tampouco trata-se de fazer da alma o objeto de um discurso verdadeiro. Estamos ainda muito longe do que seria uma hermenêutica do sujeito (FOUCAULT, 2001, p. 481, grifos nossos).

\section{O sentido do título}

E no entanto, o título tem sentido. E este sentido é duplo. “Compreendemos o próprio título do curso de 1982”, escreve expressamente F. Gros. E um pouco abaixo: “[...] no último Foucault, e particularmente acerca do estoicismo, oscilamos incessantemente entre o traçado nítido das rupturas e a insistência nas continuidades" (GROS, 2001, p. 516, grifos nossos).

Por um lado, se acentuarmos o ponto de vista histórico, entenderemos que se o Curso não trata do sujeito de uma hermenêutica, trata, porém, das condições que tornaram possível o que viria a ser uma hermenêutica do sujeito. De modo semelhante, se acentuarmos o movimento de continuidade, compreenderemos a incorporação das práticas de si pelo cristianismo na direção de uma hermenêutica do sujeito depois consolidada pelo cartesianismo. É nesta direção, cremos, que se deve ler a cuidadosa frase inicial do Resumo do Curso na qual, ao informar o tema a que "o curso deste ano foi consagrado" Foucault não diz "ao tema da hermenêutica do sujeito" mas "à formação do tema da hermenêutica de si” (FOUCAULT, 2001, p. 473, grifos nossos). Poderíamos dizer que neste primeiro sentido, A Hermenêutica do sujeito significa antes: (Em direção) à hermenêutica do sujeito.

Por outro lado, se acentuarmos o ponto de vista da genealogia, entenderemos que o Curso trata das possibilidades presentes e vindouras de superação do que veio a ser uma hermenêutica do sujeito. De modo semelhante, se acentuarmos o movimento de descontinuidade, compreenderemos a ruptura possível da hermenêutica do sujeito como passagem para outras alternativas. Poderíamos dizer que neste segundo sentido, A Hermenêutica do sujeito significa antes: (Para além) da hermenêutica do sujeito. 
Finalmente, atribuamos ao título, o que F. Gros atribui ao curso: “tem um estatuto ambíguo, quase paradoxal” (GROS, 2001, p. 489). Assim, se a curiosa hipótese a que chega o tradutor quanto ao vínculo do dito e do escrito com seu título, tem alguma justificação, é aí que ela se encontra; se há uma relação coerente do título com o que ele designa, é aí que ela reside: na sua ambiguidade quase paradoxal.

\section{REFERÊNCIAS}

ADORNO, L. P. Le style du philosophe: Foucault et le dire-vrai. Paris: Kimé, 1996.

FOUCAULT, M. L'herméneutique du sujet. Cours au Collège de France (19811982). Paris: Gallimard/Seuil, 2001. (Coll. Hautes Études).

Résumé du Cours. In: L'herméneutique du sujet. Cours au Collège

de France (1981-1982). Paris: Gallimard/Seuil, 2001. p. 473. (Coll. Hautes Études).

GROS, F. Situation du cours. In: FOUCAULT, M. L'herméneutique du sujet. Cours au Collège de France (1981-1982). Paris: Gallimard/Seuil, 2001. p. 489-526. (Coll. Hautes Études).

GROS, F. Introduction. In: GROS, F.; LÉVY, C. (Org.). Foucault et la philosophie antique. Paris: Kimé, 2003. p. 10-13.

Recebido: $17 / 11 / 2008$

Received: 11/17/2008

Aprovado: $21 / 12 / 2008$

Approved: $12 / 21 / 2008$

Revisado: 02/10/2009

Reviewed: 10/02/2009 